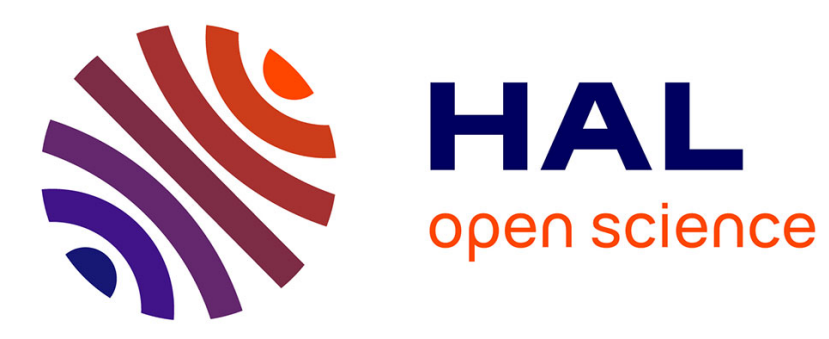

\title{
Promising reciprocity: When proposing a favor for a request increases compliance even if the favor is not accepted
}

Nicolas Guéguen, Sébastien Meineri, Clément Ruiz, Alexandre Pascual

\section{- To cite this version:}

Nicolas Guéguen, Sébastien Meineri, Clément Ruiz, Alexandre Pascual. Promising reciprocity: When proposing a favor for a request increases compliance even if the favor is not accepted. Journal of Social Psychology, 2016, 156 (5), pp.498-512. 10.1080/00224545.2015.1129304 . hal-01960565

\section{HAL Id: hal-01960565 \\ https://hal.univ-rennes2.fr/hal-01960565}

Submitted on 19 Dec 2018

HAL is a multi-disciplinary open access archive for the deposit and dissemination of scientific research documents, whether they are published or not. The documents may come from teaching and research institutions in France or abroad, or from public or private research centers.
L'archive ouverte pluridisciplinaire HAL, est destinée au dépôt et à la diffusion de documents scientifiques de niveau recherche, publiés ou non, émanant des établissements d'enseignement et de recherche français ou étrangers, des laboratoires publics ou privés. 


\section{Promising reciprocity: When proposing a favor for a request increases compliance even if the favor is not accepted}

\section{Nicolas Guéguen, Sébastien Meineri, Clément Ruiz \& Alexandre Pascual}

To cite this article: Nicolas Guéguen, Sébastien Meineri, Clément Ruiz \& Alexandre Pascual (2016) Promising reciprocity: When proposing a favor for a request increases compliance even if the favor is not accepted, The Journal of Social Psychology, 156:5, 498-512, DOI: 10.1080/00224545.2015.1129304

To link to this article: https://doi.org/10.1080/00224545.2015.1129304

Accepted author version posted online: 14

Dec 2015.

Published online: 22 Jan 2016.

Submit your article to this journal $2 \pi$

Llll Article views: 330

View Crossmark data \lceil

Citing articles: 1 View citing articles $\square$ 


\title{
Promising reciprocity: When proposing a favor for a request increases compliance even if the favor is not accepted
}

\author{
Nicolas Guéguen ${ }^{a}$, Sébastien Meineri ${ }^{\mathrm{a}}$, Clément Ruiz, ${ }^{\mathrm{b}}$ and Alexandre Pascual ${ }^{\mathrm{b}}$ \\ aUniversity of Bretagne-Sud; bUniversity of Bordeaux
}

\begin{abstract}
Research has reported that reciprocity is an important social norm in relationships. In previous studies on reciprocity, participants' behavior was examined after receiving a favor from someone. In a series of field studies, we examined the effect of a statement that proved that a solicitor was someone who respected this principle. Confederates solicited participants for money or a cigarette in exchange for stamps or money, respectively. It was found that the participants complied more readily with the request in the promised favor condition, but most of them refused to take the promised favor. We conclude that individuals were led to help those who respected the putative norm of reciprocity in their social interaction.
\end{abstract}

\section{ARTICLE HISTORY}

Received 11 March 2015

Accepted 24 November

2015

\section{KEYWORDS}

Compliance; favor; helping; norm; reciprocity

The power of the reciprocity principle has been known for a long time in the literature (Blau, 1964; Homans, 1961), and the norm of reciprocity (Gouldner, 1960) is perhaps the most widely accepted social rule in our societies. This norm implies that when a person receives a favor, he/she frequently feels that he/she ought to perform a favor in return. We know that this norm's rules of exchange are culturally different (Befu, 1980), but the norm of reciprocity seems to have a universal character in human societies (Mauss, 1966), and some authors go even so far as to speak of Homo Reciprocus (Becker, 1956). Cialdini (2009) stated that reciprocity is one of the six powerful principles of influence.

The most cited experimental research that tested the reciprocity norm on compliance with a request was performed by Regan (1971). Participants in this study worked on an art evaluation task in the same room as a confederate presented as another participant. The confederate was instructed either to do an unexpected favor for the real participant or not. In the favor condition, the confederate left the room during a break and returned with a soda for himself and the participant. In the no-favor control condition, the confederate left the room but didn't return with drinks. Some minutes later, the confederate asked the participant if he would like to purchase some raffle tickets for a high school project. It was found that participants purchased more tickets when they had first received a favor from the requester than when they hadn't received any favor. It was also found that the initial perception of the requester had no effect on reciprocity. Indeed, it was reported that the participant returned the favor even if the confederate was perceived as an unpleasant individual.

Several experimental studies have reported a consistent effect of reciprocity of an initial favor on various requests. Dommeyer, Hirao, Ikeda, Linkletter, and Watanabe (2010) reported that students who received an ice cold Coca-Cola before being solicited to participate in a survey agreed to the survey request more often. Jacob, Guéguen, and Boulbry (2015) reported the same effect when offering a single piece of candy to passersby in the street and then asking them to participate in a survey. Research has also reported that face-to-face relationships are not necessary for the reciprocation effect of an initial favor. Brennan and Charbonneau (2009) found that using chocolate as an 
incentive with a first mail-out was effective at generating a significantly higher initial response than in the control condition where no chocolate was offered.

Social psychology research has also found that compliance gaining procedures are explained by reciprocity. The Door-in-the-Face is a compliance technique that consists of asking a participant for an initial substantially larger request, which has a high probability of being refused, then submitting a second less expensive request. In this way, the $2^{\text {nd }}$ critical request has more probability of being accepted than if it were formulated directly (without the first expensive request) to the participant (Cialdini et al., 1975). For these authors, the compliance to the critical request is explained by reciprocity. The solicitor makes a concession by decreasing his/her requirement, then the participant feels a psychological obligation to make a concession and thus complies, and this pressure to reciprocate leads him to comply with the final request.

Research has also reported that some factors influence the pressure to reciprocate an initial favor received from a stranger. It has also been found that reciprocity for an initial favor exerts a stronger effect on compliance when it occurs between strangers rather than between friends (Boster, Fediuk, \& Kotowski, 2001). Whatley, Webster, Smith, and Rhodes (1999), using nearly the same methodology as Regan (1971), reported that reciprocity was higher in a public compliance situation (the favordoer asking the participant by mail to donate to a humanitarian project and asking for a name and address) than in a private compliance situation (the donation remained anonymous). Research has also reported that individual differences moderate the influence of the norm of reciprocity. Edlund, Sagarin, and Johnson (2007) reported that participants who more strongly believed in a just world were more likely to reciprocate a favor received than participants with a weaker belief in a just world. However, when no initial favor was given, belief in a just world had no impact on the reciprocation.

The research cited above reported that the effect of reciprocity occurred when the possibility to reciprocate was immediate, quasi immediate, or when a short delay was introduced. In Dommeyer et al. (2010), Jacob et al. (2015) the request was addressed to the participant immediately or quasiimmediately after receiving the favor. In Regan's (1971) study or in Whatley, et al's (1999) study, the participants were asked to reciprocate several minutes after receiving the favor, suggesting that that short of a delay between the time when the participant receives the favor and the time he/she was asked for a favor in turn, remained efficient for the effect of reciprocity to occur. However, Burger, Horita, Kinoshita, Roberts, and Vera (1997) found that when the delay between receiving a favor and reciprocating the favor increased, the probability of returning the favor decreased. In their research, participants were given an opportunity to return a favor either 5 minutes or 1 week after receiving a free soft drink from a confederate. Participants who were asked to deliver an envelope across campus comply more often in the initial favor condition than in the control no-favor condition if the request was addressed 5 minutes after the interaction with the confederate. However, when the request was addressed 1 week later, no difference between the two experimental conditions was reported. In a later study, Burger, Sanchez, Imberi, and Grande (2009) reported a reciprocation effect after 3 days. These results suggest that pressure to reciprocate decreases as time passes but also suggests that a very long delay is necessary to break the reciprocity effect.

To explain the effect of an unexpected favor on reciprocity, four theoretical explanations have been put forward. First, according to self-presentation theory (Cialdini, 2009), people return a favor in order to be perceived positively by the requester who previously did them a favor. Second, according to the internalized social norm theory (Perugini, Gallucci, Presaghi, \& Ercolani, 2003), the norm of reciprocity helps the individual to evaluate his/her own behavior. People can perceive themselves as "good" when they return the favor. Consistent with this theoretical explanation, the pressure to reciprocate explained why, in Regan's (1971) study, the participant returned the favor even if the confederate was perceived as unpleasant. Third, according to the indebtedness explanation (Greenberg \& Frisch, 1972; Greenberg \& Shapiro, 1971), after receiving an unexpected favor, an individual experiences a negative psychological state of indebtedness. Thus, in order to reduce this aversive state, the individual prefers to comply with the subsequent request in order to reduce his/her indebtedness. Fourth, according 
to Trivers (1971) reciprocating could be explained by evolution. For this author, an organism (including a human being) that helps another organism temporarily reduces its own fitness to increase the fitness of the other organism because it expects that the other organism will reciprocate help in the future. Other evolutionary scientists (Ridley, 1997; Wrigth, 1994) also state that we help others because of natural and instinctual pressure to do so, and this natural tendency leads us as individuals to internalize the norm of reciprocity. Of course, these various explanations are not exclusive, and reciprocating favors in human relationships and societies is probably polygenetic and explained by several processes.

Taken all together, the studies reported above show that an initial favor from a stranger is a good method for obtaining more compliance with a subsequent request made by the benefactor. The objective of the present paper is not to further examine the effect of an initial favor but to more readily study some principles associated with the norm of reciprocity. Perhaps participants comply after receiving the initial favor because they perceived the solicitor as respecting the balance in the exchange. In this way, when someone gives me something, I want to give him/her something in return in order to restore the balance of the exchange. Thus, it could be stated that a solicitor who does not give me anything at the beginning of the interaction, but who states that he/she wants to give me something in return, will be perceived as someone who respects the principles of balance associated with the norm of reciprocity. Consequently, the participant will comply more readily with the solicitor's request without accepting the promised favor. Four experiments conducted in a natural setting tested this hypothesis. In a fifth experiment, we tried to examine the perception of the solicitor who either promised a favor or did not.

\section{Study 1}

\section{Method}

\section{Participants}

The participants were 160 (80 males and 80 females) passersby (between 30 and 50 years of age in appearance) chosen at random while they were walking alone in pedestrian areas of a town (around 70,000 inhabitants) situated on the south coast of Brittany in France.

\section{Procedure}

A 21-year old undergraduate man served as a confederate in this study. The confederate stationed himself in the street and chose a participant walking in his direction. If a child, an adolescent, an older person, or a group of people passed, the confederate waited until a person corresponding to the profile (men or women of roughly 30 to 50 years of age, alone) walked by. In the promised favor condition, the confederate approached the participant, politely saying to him or her, "Hello, sir/madam. I am sorry to disturb you, but I have forgotten my change purse and I wonder if you could give me some money for the bus, and I will give you these two stamps in exchange (The confederate showed the two stamps that have a total value of $€ 1.20)$." In the control condition the confederate just said to the participant "Hello, sir/ madam. I am sorry to disturb you but I have forgotten my change purse and I wonder if you could give me some money for the bus." In both experimental conditions, the confederate waited for the passerby's response. In the promised favor condition, if the participant gave some money to the confederate, then the latter held out his hand with the two stamps and said "Thanks sir/madam; here are the two stamps." The confederate noted whether the participant took the two stamps or not. The participant was then fully debriefed. 


\section{Results and discussion}

The number of participants who complied with the money request addressed by the confederate was the dependent variable in this study. The results are presented in Table 1.

To account for the effects that the variables may have had, a 2 (participant gender) $\times 2$ (experimental condition) log-linear analysis using the frequency of compliance/non-compliance as the measure of the dependent variable was used.

Two distinctive analyses were performed. The first used the total participants who complied in the promised favor condition, whether they took the two stamps or not. The analysis reported a main effect of experimental conditions, $\chi^{2}(1)=9.14, p=.002, \phi=.24$, revealing that, overall, more participants comply in the promised favor condition (41.3\%) than in the control condition (20.0\%). A main effect of participant gender was found, $\chi^{2}(1)=9.14, p=.002, \phi=.24$, and showed that women gave significantly more often $(41.3 \%)$ than men $(20 \%)$. However, the interaction effect between participant gender and experimental condition was not statistically significant, $\chi^{2}(1)=0.64$, $p=.799, \phi=.07$.

The second analysis used the number of participants who complied in the promised favor condition and who refused to take the two stamps offered. The analysis reported a main effect of experimental conditions, $\chi^{2}(1)=5.53, p=.019, \phi=.24$, revealing that, overall, more participants comply in the promised favor condition (36.3\%) than in the control condition (20.0\%). A main effect of participant gender was found, $\chi^{2}(1)=7.31, p=.007, \phi=.22$, and revealed that women gave significantly more often $(37.5 \%)$ than men (18.8\%). Again, the interaction effect between participant gender and experimental condition was not statistically significant, $\chi^{2}(1)=0.01, p=.997, \phi=.00$.

The results supported the assumption that promising a favor in return for a requested favor increased compliance with the request. This effect was found both with male and female participants. The effect of the favor appeared significant whether or not the comparison was performed by including those participants who took the two stamps in the promised favor condition. Thus, these results suggest that a single promise of a favor addressed after the request for money increased compliance. We also reported that few participants took the stamps: 5\% (4/80) when compared with the total number of participants tested, and 12\% (4/33) when compared only with participants who accepted to give money. Thus, it seems that the desire to obtain the two stamps in exchange for the money given was not the primary reason for which the participants complied. Proposing the two stamps in exchange appeared efficient for gaining compliance because the confederate respected the value related to the norm of reciprocity.

Study 1 was the first trial for testing the effect of a promised favor. The objective of the second study was to replicate this first study using a stronger methodology and to extend it. First, a larger sample size was used in this second study, and the amount of money left by the participant was measured. Second, two different promised favor conditions were used: one similar to the method used in Study 1 and another where the confederate promised the two stamps but without presenting them when asking for bus money.

Table 1. Frequency and percent of participants who complied with the confederate request according to experimental condition and the sex of participants.

\begin{tabular}{lcc} 
& & Control condition \\
\hline Male pedestrians & Promised favor condition & \\
Compliance and favor refused & $25.0 \%(10 / 40)$ & $12.5 \%(5 / 40)$ \\
Compliance and favor accepted & $2.5 \%(1 / 40)$ & \\
Total compliance & $27.5 \%(11 / 40)$ & \\
Female pedestrians & & \\
Compliance and favor refused & $47.5 \%(19 / 40)$ & $27.5 \%(11 / 40)$ \\
Compliance and favor accepted & $7.5 \%(3 / 40)$ & $50 \%(22 / 40)$ \\
Total compliance & $55.0 \%$ & \\
\hline
\end{tabular}




\section{Study 2}

\section{Method}

\section{Participants}

The participants were 480 (240 males and 240 females) passersby (between 30 and 50 years of age in appearance) chosen at random while they were walking alone in pedestrian areas of a town (around 70,000 inhabitants) situated on the south coast of Brittany in France.

\section{Procedure}

Four 19- to 20-year-old undergraduate women served as confederates in this study. All were neatly dressed as young people of their age. The method used to approach a participant was exactly the same as in Study 1, and the same sentences were used. However, two promise conditions were introduced. One condition (promised favor with stamps presented) used the same methodology as in Study 1 . In the other promise condition (promised favor without stamps presented), the confederate promised to give the participant two stamps, but these two stamps were not held out in the confederate's hand. Of course, when the participant accepted to give money, the confederate took the two stamps contained in her pocket and offered them to the participant in exchange for his/her donation. In both promised avour conditions, if the participant gave some money to the confederate, the latter took the money in her hand, and with the two stamps in her other hand said "Thanks, sir/ madam; here are the two stamps." The confederate noted whether or not the participant took the two stamps. In all the conditions, the amount of money left by the participant was measured (the price of a bus ticket when the study was carried out was $€ 1.50$ ). The confederate was instructed to test 10 participants ( 5 men and 5 women) in each condition and then to change the condition. The order of the experimental conditions was randomized.

\section{Results and discussion}

The number of participants who complied with the survey request addressed by the confederate and the amount of money left were the two dependent variables measured in this study. The results are presented in Table 2 .

\section{Compliance}

To account for the effects that the variables may have had on compliance with the request, a 2 (participant gender) $\times 3$ (experimental condition) log-linear analysis using the frequency of compliance/non-compliance as the measure of the dependent variable was used. As previously, two distinctive analyses were performed.

The first used the total participants who complied in the two promised favor conditions whether they took the two stamps or not. The analysis reported a main effect of experimental conditions, $\chi^{2}(2)=24.64, p<.001, \phi=.23$. Further comparison revealed that the condition involving the promised favor with stamps presented was significantly higher than the condition involving the promised favor without stamps presented, $\chi^{2}(1)=5.27, p=.13, \phi=.18$, and significantly different than the control condition, $\chi^{2}(1)=24.07, p<.001, \phi=.27$, while the condition involving the promised favor without stamps presented exceeded the control condition, $\chi^{2}(1)=7.17, p=.007, \phi=.15$. Neither the main effect of participant gender, $\chi^{2}(1)=1.22$, $p=.270, \phi=.05$, nor the interaction effect between participant gender and experimental condition, $\chi^{2}(1)=0.57, p=.756, \phi=.03$, appeared significant.

The second analysis used the number of participants who complied in the two promised favor conditions and who refused to take the two stamps offered. The analysis reported a main effect of experimental conditions, $\chi^{2}(2)=19.52, p<.001, \phi=.20$. 
Table 2. Frequency of participants who complied with the confederate survey request and amount of money (in euros) according to experimental condition and the sex of participants.

\begin{tabular}{|c|c|c|c|}
\hline Group & $\begin{array}{c}\text { Promised favor condition with stamp } \\
\text { presented }\end{array}$ & $\begin{array}{l}\text { Promised favor condition without stamps } \\
\text { presented }\end{array}$ & $\begin{array}{l}\text { Control } \\
\text { condition }\end{array}$ \\
\hline \multicolumn{4}{|l|}{$\begin{array}{l}\text { Frequency of donation } \\
\text { Male pedestrians }\end{array}$} \\
\hline $\begin{array}{l}\text { Compliance and favor } \\
\text { refused }\end{array}$ & $40.0 \%(32 / 80)$ & $31.3 \%(25 / 80)$ & \\
\hline $\begin{array}{l}\text { Compliance and favor } \\
\text { accepted }\end{array}$ & $0.0 \%(0 / 80)$ & $0.0 \%(0 / 80)$ & \\
\hline Total compliance & $40.0 \%(32 / 80)$ & $31.3 \%(25 / 80)$ & $18.8 \%(15 / 80)$ \\
\hline \multicolumn{4}{|l|}{ Female pedestrians } \\
\hline $\begin{array}{l}\text { Compliance and stamps } \\
\text { refused }\end{array}$ & $43.8 \%(35 / 80)$ & $28.8 \%(23 / 80)$ & \\
\hline $\begin{array}{l}\text { Compliance and stamps } \\
\text { accepted }\end{array}$ & $6.3 \%(5 / 80)$ & $5.0 \%(4 / 80)$ & \\
\hline Total compliance & $50 . \%(40 / 80)$ & $33.8 \%(27 / 80)$ & $20.0 \%(16 / 80)$ \\
\hline \multicolumn{4}{|l|}{$\begin{array}{l}\text { Mean of donation (SD in } \\
\text { brackets) }\end{array}$} \\
\hline \multicolumn{4}{|l|}{ Male pedestrians } \\
\hline $\begin{array}{l}\text { Compliance and favor } \\
\text { refused }\end{array}$ & $0.92(0.23)$ & $0.91(0.21)$ & \\
\hline $\begin{array}{l}\text { Compliance and favor } \\
\text { accepted }\end{array}$ & $0.00(0.00)$ & $0.00(0.00)$ & \\
\hline Total mean & $0.92(0.23)$ & $0.91(0.21)$ & $0.79(0.25)$ \\
\hline \multicolumn{4}{|l|}{ Female pedestrians } \\
\hline $\begin{array}{l}\text { Compliance and stamps } \\
\text { refused }\end{array}$ & $0.99(0.21)$ & $0.90(0.20)$ & \\
\hline $\begin{array}{l}\text { Compliance and stamps } \\
\text { accepted }\end{array}$ & $1.00(0.00)$ & $0.75(0.29)$ & \\
\hline Total mean & $0.99(0.28)$ & $0.88(0.21)$ & $0.74(0.27)$ \\
\hline
\end{tabular}

Pairwise comparison revealed that the condition involving the promised favor with stamps presented was significantly higher than the condition involving the promised favor without stamps presented, $\chi^{2}(1)=4.90, p=.031, \phi=.13$, and it was significantly different than the control condition, $\chi^{2}(1)=19.06, p<.001, \phi=.25$, while the condition involving the promised favor without stamps presented exceeded the control condition, $\chi^{2}(1)=4.86, p=.027, \phi=.12$. Neither the main effect of participant gender, $\chi^{2}(1)=0.41, p=.840, \phi=.04$, nor the interaction effect between participant gender and experimental condition, $\chi^{2}(1)=0.35, p=.843, \phi=.03$, appeared significant.

\section{Amount of money left}

With the amount of the money left by the participants, a 2 (participant gender) $\times 3$ (experimental condition) between groups analysis of variance (Anova) was performed. As with compliance with the request, two distinctive analyses were performed.

The first used the total participants who complied in the two promised favor conditions whether they took the two stamps or not. The analysis reported a main effect of experimental conditions $\left(F(2,149)=6.53, p=.002, \eta_{p}^{2}=.081\right)$. Post hoc comparison revealed that, compared to the control, more money was donated in the promised favor with stamps condition, LSD test, $p<.001$, and also in the promised favor without stamps condition, LSD test, $p=.02)$. However, we reported no significant difference between the two promised favor conditions (LSD test, $p=.15$ ). Neither the main effect of participant gender, $F(1,149)=0.05$, $p=.968, \eta_{p}{ }^{2}<.005$, nor the interaction effect between participant gender and experimental condition, $F(2,149)=1.01, p=.368, \eta_{p}^{2}=.013$, appeared significant.

The second analysis used the number of participants who complied in the two promised favor conditions and who refused to take the two stamps offered. The analysis reported a main effect of 
experimental conditions, $F(2,140)=6.23, p=.003, \eta_{p}{ }^{2}=.082$. Post hoc comparison revealed that more money was donated in the condition involving the promised favor with stamps presented than the control condition, LSD test, $p<.001$, as well as for the condition involving the promised favor without stamps presented compared to the control condition, LSD test, $p=.014$. However, we reported no significant difference between the two promised favor conditions (LSD test, $p=.293$ ). Neither the main effect of participant gender $\left(F(1,140)=0.15, p=.903, \eta_{p}{ }^{2}<.005\right)$ nor the interaction effect between participant gender and experimental condition $(F(2,149)=0.757$, $\left.p=.471, \eta_{p}^{2}=.011\right)$ appeared significant.

Using a large sample size, the results supported the assumption that promising a favor in return for a solicited favor increased compliance with the request. This effect was found both with male and female participants. Interestingly, we did not report an overall difference between male and female participants in this study. Comparison with the first study shows that more men helped the female confederate than in Study 1, where a male confederate was used.

The effect of the favor appeared significant whether or not the comparison was performed by including those participants who took the two stamps in the promised favor condition. Again, we reported that few participants took the stamps (3\% (9/320) when compared with the total number of participants tested, and 7\% (9/124) when compared only with participants who accepted to give money). Again, such a low rate of participants who took the two stamps suggested that the reason to donate more frequently in the promised favor conditions is not explained by the need to take the two stamps offered in exchange.

Two interesting additional results were reported in this second study. First, we found that in both experimental conditions, participants gave larger amounts of money than those in the control condition, suggesting a strong effect of the promised favor on the desire to help the confederates. Second, we reported that the effect of the promised favor is higher when the confederate showed the two stamps offered in exchange than when she just asked and expressed the intent to offer them in exchange. This difference could suggest that the participant attributed more confidence to the confederate's promise to return the requested favor. However, we also found that the presence of the stamps was not a condition for the promised favor to work. Indeed, we observed a significant difference between the promised favor without stamps presented condition and the control condition. This result suggests that the effect of the promise is explained by the promise favor per se and not by the possibility to easily obtain the two stamps.

The objective of the third study was to examine the effect of the difference between the value of the promised favor and the value of the favor the participant was asked for in exchange. Indeed, we hypothesized that the norm of reciprocity is probably influenced by the balance of the exchange between the cost of the favor asked of the participant and the cost of the favor returned by the solicitor. When the solicitor gives more than the value of the favor solicited, the pressure to reciprocate is probably higher and thus compliance will be higher. This was examined in this third study using a new solicitation. A confederate asked for 1 euro for the parking meter and promised to give something in exchange. In this experiment, the favor solicited by the confederate remained the same, but according to the experimental condition, the value of the favor promised by the confederate became successively higher.

\section{Study 3}

\section{Method}

\section{Participants}

The participants were 320 (160 males and 160 females) passersby (between 30 and 50 years of age in appearance) chosen at random while they were walking alone in pedestrian areas of a town (around 70,000 inhabitants) situated on the south coast of Brittany in France. 


\section{Procedure}

Two 20-year-old undergraduate women served as confederates in this study. In this later study, the request addressed to the participant was different from Study 1 and Study 2.

In the promised favor condition, the confederate approached the participant, politely saying to him or her, "Hello, sir/madam. I am sorry to disturb you, but I have forgotten my change purse, and I wonder if you could give me one euro for the parking meter, and I will give you these X stamps (The confederate showed the stamps) in exchange." According to the favor condition, the confederate offered two, three, or four stamps in exchange. In the control condition, the confederate just said the same to the participant but did not propose any favor in return. In both experimental conditions, the confederate waited for the passerby's response. In the promised favor condition, if the participant gave some money to the confederate, then the latter held out his hand with the two/three/four stamps and said, "Thanks, sir/madam; here are the stamps." The confederate noted whether or not the participant took the stamps. The participant was then fully debriefed.

\section{Results and discussion}

The number of participants who complied with the money request addressed by the confederate was the dependent variable in this study. The results are presented in Table 3.

To account for the effects that the variables may have had, a 2 (participant gender) $\times 4$ (experimental condition) log-linear analysis using the frequency of compliance/non-compliance as the measure of the dependent variable was used. Two distinctive analyses were done.

The first used the total participants who complied in the promised favor condition whether they took the stamps or not. The analysis reported a main effect of experimental conditions, $\chi^{2}(3)=26.73$, $p<.001, \phi=.03, \phi=.29$. Further comparisons revealed that the three promised favor conditions exceeded the control condition. However, we reported no significant difference between the three promised favor conditions, except there was less compliance in the 2-stamp condition than the 4stamp condition, $\chi^{2}(1)=3.27, p=.07, \phi=.14$. A main effect of participant gender was found, $\chi^{2}$ $(1)=7.17, p=.007, \phi=.15$, revealing that women helped the confederate more often $(36.3 \%)$ than men $(23.1 \%)$. However, the interaction effect between participant gender and experimental condition was not significant $\left(\chi^{2}(3)=0.37, p=.998, \phi=.03\right)$.

The second analysis used the number of participants who complied in the three promised favor conditions and who refused to take the offered stamps. The analysis reported a main effect of the experimental conditions, $\chi^{2}(3)=26.55, p<.001, \phi=.29$. Further comparisons revealed that the three promised favor conditions exceeded the control condition. The 4-stamp condition was significantly above the 2-stamp condition, $\chi^{2}(1)=9.23, p=.002, \phi=.24$, and the 3-stamp condition, $\chi^{2}(1)=3.89$, $p=.048, \phi=.16$, while the difference between the 2 -stamp condition and the 3 -stamp condition was not statistically significant, $\chi^{2}(1)=1.20, p=.271, \phi=.09$. A main effect of participant gender was found, $\chi^{2}(1)=7.86, p=.005, \phi=.16$, and revealed that women gave more often $(32.5 \%)$ than men

Table 3. Frequency and percent of participants who complied with the confederate request according to experimental condition and the sex of participants.

\begin{tabular}{|c|c|c|c|c|}
\hline & \multicolumn{3}{|c|}{ Promised favor conditions } & \multirow[b]{2}{*}{ Control condition } \\
\hline & 2 stamps & 3 stamps & 4 stamps & \\
\hline \multicolumn{5}{|l|}{ Male pedestrians } \\
\hline Compliance and favor refused & $15.0 \%(6 / 40)$ & $25.0 \%(8 / 40)$ & $35.0 \%(14 / 40)$ & \\
\hline Compliance and favor accepted & $7.5 \%(3 / 40)$ & $2.5 \%(2 / 40)$ & $0.0 \%(0 / 40)$ & \\
\hline Total compliance & $22.5 \%(9 / 40)$ & $27.5 \%(11 / 40)$ & $35.0 \%(14 / 40)$ & $7.5 \%(3 / 40)$ \\
\hline \multicolumn{5}{|l|}{ Female pedestrians } \\
\hline Compliance and favor refused & $25.0 \%(11 / 40)$ & $37.5 \%(15 / 40)$ & $52.5 \%(21 / 40)$ & \\
\hline Compliance and favor accepted & $10.0 \%(4 / 40)$ & $5.0 \%(2 / 40)$ & $0.0 \%(0 / 40)$ & \\
\hline Total compliance & $37.5 \%(15 / 40)$ & $42.5 \%(17 / 40)$ & $52.5 \%(21 / 40)$ & $12.5 \%(5 / 40)$ \\
\hline
\end{tabular}


(19.4\%). Again, the interaction effect between participant gender and experimental condition was not s significant, $\chi^{2}(3)=0.122, p=.989, \phi=.02$.

In this third study, using a new dependent variable, we reported again that the promised favor increased compliance with the confederate's request. Thus, our results, combined with those reported in the two previous studies, suggest the robustness of the promised favor on compliance. More interestingly, we reported in this third study that the effect of the promised favor increased as soon as the cost of the favor promised in return for the request increased. In this study, we reported that more participants complied in the 4-stamp promised favor condition than in the 3-stamp or in the 2-stamp conditions. This suggested that when the cost of the solicitor's returned favor is larger than the cost of the request solicited, the pressure for the participants to reciprocate is higher.

The objective of the fourth study was to more readily examine the effect of the value of the promised favor on the willingness to reciprocate. In this study, the favor was lower or considerably higher than the value of the request.

\section{Study 4}

\section{Method}

\section{Participants}

The participants were 864 (507 males and 357 females) passersby (between 20 and 45 years of age in appearance) smoking a cigarette, solicited while they were walking alone in pedestrian areas of four towns (from around 70,000 inhabitants to 300,000) situated on the south coast of Brittany in France.

\section{Procedure}

Twelve undergraduate business students ( 8 men and 4 women), aged between 19 to 22 acted as confederates in this experiment. They were dressed neatly and in a casual manner for young people of their age (clean jeans and a tee-shirt, common standard shoes). Confederates were instructed to approach a participant, smoking a cigarette in the street.

In the five experimental conditions, the confederate politely said to the participant: "Excuse me, would you give me a cigarette please? I will pay you $x$ for it in return". Depending on the experimental condition, the amount proposed was: $€ 0.10, € 0.30, € 0.50, € 1$ or $€ 2$. The confederate held the coin in his hand and clearly showed it to the participant. In France, at the time when the present experiment was carried out, the cost of one cigarette varied from 0.30 to 0.35 . In the control condition, the confederate approached the participant and made the following request in a polite way: "Excuse me, would you give me a cigarette please?" After having solicited the participant, the confederate noted if the participant gave him/her or not the solicited cigarette. The confederate noted whether the participant took the money or not. The confederate then debriefed the participant. Each confederate was instructed to test 12 participants in each experimental condition. The order of the conditions was randomized.

\section{Results and discussion}

The number of participants who complied with the money request addressed by the confederate was the dependent variable in this study. The results are presented in Figure 1.

In this study, we did not find any participant who accepted the change in return for their favor. A Chi-square independent test crossing the six experimental conditions and the frequency of compliance/non-compliance was used. An overall significant effect was reported, $\chi^{2}(5)=60.71, p<.001$, $\phi=.26$, revealing a significant difference between all the experimental conditions. Pairwise comparison revealed that the control condition was significantly below the $€ 0.30$ condition, $\chi^{2}(1)=8.80$, $p=.003, \phi=.17$, and all the further higher-value conditions, but not different from the $€ 0.10$ condition, $\chi^{2}(1)=0.77, p=.378, \phi=.05$. The $€ 0.10$ condition appeared significantly different from 


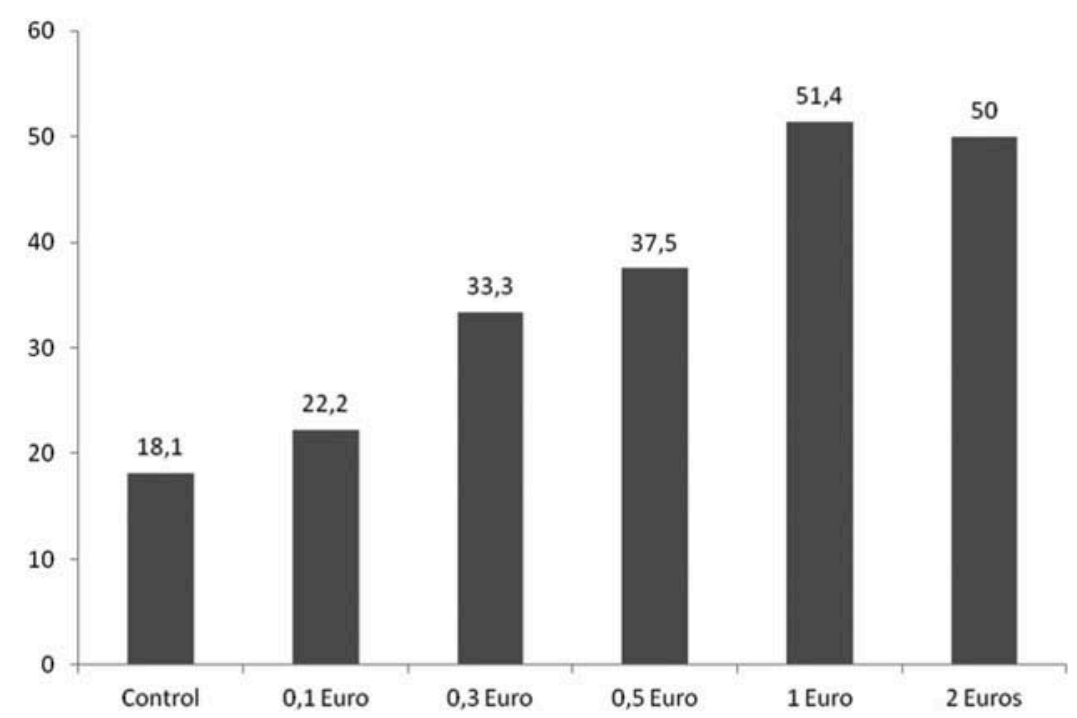

Figure 1. Percent of participants who complied with the confederate request according to experimental condition $(N=72$ in each condition).

all the further promised money conditions. Further analysis reported that the $€ 0.30$ condition was significantly below the $€ 1$ condition, $\chi^{2}(1)=9.61, p=.002, \phi=.18$, and the $€ 2$ condition $\left(\chi^{2}\right.$ $(1)=8.22, p=.004, \phi=.17)$. Finally, the $€ 0.50$ condition approached significance when compared with the $1 €$ condition, $\chi^{2}(1)=3.58, p=.058, \phi=.11$, but was not significantly different from the $€ 2$ condition, $\left(\chi^{2}(1)=2.75, p=.097, \phi=.10\right.$.

Using a new request (asking for a cigarette) and a new form of promised favor in return (change) we confirmed with a very large sample size that promising to reciprocate a favor led the participant to comply more readily with the request even if the favor promised in return was refused. In this study, among the 284 participants who accepted to give the solicited cigarette, none accepted the change offered in return. Our results also confirmed that the amount of the promised exchange was an important factor to control. In this study, we reported that the promised exchange exerted no effect of compliance when the amount promised was lower than the value of the cigarette solicited $(€ 0.10)$. As soon as the promised amount became identical to the value of the cigarette solicited, then the promise to reciprocate operated (0.30). This suggested that the effect of the influence of the responsibility norm on influence probably occurs when the balance between the request and the promised favor appears equilibrated for the participant. We also reported that compliance increased when the amount of the money promised for the cigarette was clearly higher than the average value of a cigarette. Congruent with the findings reported in Study 3, this would probably mean that when the cost of the favor promised by the solicitor is larger than the cost of the request solicited, the participant experienced more pressure to reciprocate, which in turn increased compliance.

The objective of Study 5 was to examine the participant's impression of the solicitor. It could be hypothesized that, given the importance of the reciprocity norm in human relationships, those who respect the principles of reciprocity by offering something in return for a solicited favor will be perceived more favorably. This later study tested this hypothesis.

\section{Study 5}

\section{Method}

\section{Participants}

The participants were 160 passersby smoking and walking alone in pedestrian areas of a town (nearly 300,000 inhabitants) situated on the south of the Atlantic coast in France. 


\section{Procedure}

A 22-year-old male confederate was instructed to approach a participant smoking a cigarette in the street and to ask him/her for a cigarette. The same procedure as the one used in Study 4 was employed. However, in this study, only the control condition and the $€ 1.00$ promised favor condition were used. The order of the conditions was randomized. The confederate acted the same way as previously. The confederate asked the participants who complied with the request to respond to a short questionnaire associated with the perception of the confederate and his behavior. The survey contained five scales measuring how likeable or honest the confederate was perceived to be. The participant was also asked to evaluate the general impression created by the confederate. Then the participant was asked to evaluate if they thought that the confederate was used to soliciting cigarettes in the street and how obliged the participant felt to donate. An 8-point scale was used to measure the responses of the participant, ranging from 0 (not very honest, not very kind...) to 8 (honest, kind...). After responding, the participant was fully debriefed. The confederate ended surveying the participants when he had reached 20 participants in each experimental condition.

\section{Results and discussion}

In the control condition, $35 \%$ of the participants complied (28/80), whereas there were $65 \%(52 / 80)$ in the promised favor condition, and the difference was significant, $\chi^{2}(1)=14.4, p<.001, \phi=.28$. The data provided from the scales are presented in Table 4 . The difference between the two groups was analyzed with the help of Student's $t$ test. Since multiple statistical tests were used with the same data set, we increased the probability of a Type I Error. Accordingly, Bonferroni's adjustment was used to compensate for this increased probability, which consisted in dividing the alpha level (0.05) by the number of separate pairwise comparisons. In this experiment, the alpha level with Bonferroni's adjustment was equal to 0.01 , and the critical t-value for double-sided testing $(d f=38)$ was equal to 2.43 . In all the pair-wise comparisons except one, the calculated $t$ value was lower than 2.43 . We only reported a significant difference when examining the perceived level of the confederate's habit of soliciting: Participants in the promise condition perceived less of a habit.

The results of this study confirmed the robustness of the promised favor technique to increase compliance with a request. The evaluation of the participant's judgment showed that promising a favor in exchange for a request did not change the perception of the confederate. The latter is not perceived to be more kind or honest in the promise condition, and we reported no change between the two groups on the measure of the overall impression created by the confederate. In some way, these results are congruent with those reported by Regan (1971), who found that participants returned the favor to a confederate who had previously offered them a Coca-Cola even if the confederate was instructed to act unpleasantly at the beginning of the study. This suggests that a good impression is not the factor that explains the effect of the promised favor.

We did not report that the feeling of obligation to donate was higher in the promise condition, suggesting that a feeling of obligation to reciprocate is not the mediating factor that explains the promised favor effect. However, it could be suggested that we found no difference because of a bias in the response of a participant who wanted to give a positive impression of someone who is free to donate or not (the means in both conditions were closer to 0 (no obligation) than 8 (high

Table 4. Means (SD in brackets) of the evaluation scales according to the experimental conditions (a higher score is associated with a better positive evaluation).

\begin{tabular}{llll}
\hline & Control & Promised favor & Test \\
\hline Friendly & $6.05(1.82)$ & $5.75(2.69)$ & $t(38)=0.41, p=.682$ \\
Honest & $5.35(2.27)$ & $6.35(2.50)$ & $t(38)=1.32, p=.193$ \\
General impression & $6.25(2.07)$ & $6.25(1.58)$ & $t(38)=0.00, p=1.00$ \\
Habit of soliciting & $5.25(1.20)$ & $3.05(2.86)$ & $t(38)=3.17, p=.003$ \\
Obligation to donate & $2.80(3.00)$ & $2.85(2.80)$ & $t(38)=0.05, p=.957$ \\
\hline
\end{tabular}


obligation). As the norm of reciprocity is considered an internalized social norm (Burger et al., 2009; Whatley et al., 1999), it could also be argued that the participants are not clearly conscious of the pressure to reciprocate. We reported that the participant perceived the confederate as someone who was not used to soliciting cigarettes. It could be stated that the participant clearly perceived that offering money in return for a request is clearly perceived as unusual. However, the increase in this perception is not accompanied by greater pressure to comply with the request. Thus, overall this later study seems to eliminate possible psychological mediators of the effect of the promised favor on later compliance.

\section{General discussion}

In five studies involving 1,984 participants, we consistently reported that promising a favor in exchange for a request increased compliance with the request even though a very large majority of the participants refused to accept the offered favor after complying. The mean of the effect-size of compliance with the request was moderate, $M=0.26, S D=0.03$, but appeared identical to some studies measuring compliance when an initial favor is given $(\phi=.29$ in Burger et al. (2009), $\phi=.28$ in Jacob et al. (2015), $\phi=.28$ in Burger et al. (1997)), suggesting that promising a favor for help or giving a favor before asking for help has the same effect on compliance.

We also reported that the effect of the promised favor was found both with male and female participants, suggesting the generalization of these findings across gender. In Studies 1, 2, and 3, where data analysis was also performed with those who refused the stamps offered in exchange for the request, we reported a significant effect of the promised favor technique. These results suggest that the effect of the promised favor is not explained by the need to simply exchange something with another. In previous studies examining the effect of a first favor on a later returned favor, participants were first offered something: a Coca-Cola (Dommeyer et al., 2010; Regan, 1971), a candy or a chocolate (Brennan \& Charbonneau, 2009; Fairweather, 2010; Jacob et al., 2015) or a coin (Brennan, Hoek, \& Gendall, 1998). In these studies, the incentive was unexpected and appeared to be a form of in-kind payment for the solicited request addressed later. It could be stated that compliance with the request could be considered as a form of repayment for the unexpected favor. Thus, a balance existed between the unexpected received favor and the returned favor. This is not the case in our own experiments where the reward for the request was offered and not given without the consent of the participant. However, the participant refused the offered favor, suggesting that the search for a single economic balance in the interaction (Foa \& Foa, 2012) is not the process that could explain compliance in our studies, because nearly all the participants refused the favor offered by the confederate in exchange. It seems that participants complied more in the promised favor condition because the virtual principle of reciprocity was respected in this study.

The question that now remains is to explain the results reported in these studies. The norm of reciprocity implies that when a person receives a favor, he/she frequently feels that he/she ought to return a favor (Gouldner, 1960). This principle could explain the results reported in previous studies cited (Brennan \& Charbonneau, 2009; Dommeyer et al., 2010; Jacob et al., 2015; Regan, 1971). With our results, it seems that the norm of reciprocity also implies that we favor those who have the intent to reciprocate. Thus, we give to those who have previously given us something, but we also give to those who intend to give us something. This suggests that the norm of reciprocity is not based on a strict economic balance but also implies that we help those who respect the principle of reciprocity. In our studies, the promised favor must have shown that the requester respected the principle of reciprocation. In this way, the participant was led to comply more favorably with the request but refused the promised favor, because respecting the principle of reciprocity is probably more important than having an economic balance. In Study 5, we did not report any difference between the two groups when we evaluated the perceived obligation to help. This result suggested that the pressure to reciprocate, which could explain the results of previous studies on an unexpected favor on later compliance with a request (Brennan \& Charbonneau, 2009; Dommeyer et al., 2010; Jacob 
et al., 2015; Regan, 1971), is not an explanation for our own results and suggests that respecting the principle of reciprocation is sufficient to influence compliance. We clearly found no difference in the perception of the confederate in the two experimental conditions.

Again, these findings suggest that the effect of the promised favor occurred here not because the participants perceived the solicitor differently, but because the norm of the reciprocity principle, a universal character in human societies (Mauss, 1966), was respected. In some way, our participants seem to act as an automatic Homo Reciprocus (Becker, 1956). Such results are congruent with evolutionary theorists (Ridley, 1997; Trivers, 1971; Wright, 1994) who stated that the norm of reciprocity is internalized naturally and instinctively. In the same way, Burger et al. (2009) also stated that the norm of reciprocity is an inherited characteristic leading the individual to return a favor not only for self-interest but also to help groups of individuals and societies survive.

Our results suggest that showing somebody who respects the reciprocity norm is something important in social relationships. In the previous studies on this topic (Burger et al., 2006; Jacob et al., 2015; Regan, 1971; Whatley,Webster, Smith, \& Rhodes 1999), a gift was given to the participant before requesting something in return, suggesting that people paid what they received even if the gift was unintended and/or presented no interest for the participant. In Study 5, we reported that the solicitor was perceived in the same way in both conditions, suggesting that proposing something in exchange does not change how we perceive the individual. Perhaps, showing that someone respects the norm of reciprocity does not change how we perceive the individual but rather leads the participant to have a confirmation that the norm necessary for the survival of the group and society is well present, which in turn leads the participant to help the requester. Showing that an unknown individual respects this norm could constitute as proof that the norm exists and is shared in the community.

Our results also showed that the effect of the promised favor increased when its value increased. By offering more in exchange, the confederate could be perceived to have a higher need, which in turn led the participant to comply more readily with the request. Research on helping behavior has reported that the perceived need of the requester influences helping (Bickman \& Kamzan, 1973; Harrel \& Goltz, 1980). A higher promised favor could also lead the participant to perceive high legitimacy in the confederate's request, and research also reports that legitimacy increases helping (Innes \& Gilroy, 1980). These findings could also suggest that the confederate, by offering more in exchange, respected the principle of reciprocity at a high level. Thus, these results suggest that a strict economic balance is not the way to explain our results. When the participant had the opportunity to gain more than to lose (when the value of the promised favor was larger than the cost of the favor solicited), he/she complied more often and refused the promised favor more often.

\section{Limitations and future studies}

Of course, these studies presented several limitations that need further studies. First, we used very low-cost requests (one coin, a cigarette) in these studies. This probably also explains why most of the people refused to take the favor proposed by the confederate in return. However, it could be interesting to evaluate the effect of more costly requests on an individual's behavior. In all these studies, the confederate formulated his request and immediately proposed something in turn. It would also be interesting to test a greater delay in proposing the promised favor. For example, it could be interesting to ask participants for a favour, and with those who refused, wait several minutes and return to address the promised favor. At last, in study 5, we reported no effect of the promised favor on how we perceived the requester and the perceived obligation to reciprocate. However, it could be interesting to investigate further dimensions such as indebtedness or self-presentation. 


\section{Conclusion}

In conclusion, our results reported that when promising something in return for a solicited favor, more help is received even if in the end the helper refuses the promised favor. These findings suggest that the effect of the norm of reciprocity is only not explained by a principle that states that we feel obliged to return a favor to those who have given us something. Our results suggest that a strict economic exchange does not explain why participants comply more. We must conclude that as the norm of reciprocity is a universal character in human societies, interacting with someone who respects the principle of this norm is sufficient to influence our helping behavior.

\section{Notes on contributors}

Nicolas Guéguen, $\mathrm{PhD}$, is currently Professor of Social Behavior and Social Marketing at the University of BretagneSud in France. His research interests are related with compliance-gaining techniques and consumer behavior. Sébastien Meineri, PhD, is currently Associate Professor of Social Behavior at the University of Bretagne-Sud in France. His research interests are related with compliance-gaining techniques for effecting behavior change in relation with ecology (e.g., recycling, transit use). Clément Ruiz is an undergraduate student at the University of Bordeaux. His research interests are related with compliance-gaining techniques. Alexandre Pascual, $\mathrm{PhD}$, is currently Associate Professor of Social Behavior at the University of Bordeaux 2 in France. His research interests are related with compliance-gaining techniques.

\section{References}

Becker, H. (1956). Man on reciprocity. New York, NY: Praeger.

Befu, H. (1980). Structural and motivational approaches to social exchange. In K. Gergen, M. Gergen, \& R. Willis (Eds.), Social exchange: Advances in theory and research (pp. 197-124). New York, NY: Plenum.

Bickman, L., \& Kamzan, M. (1973). The effect of race and need on helping behavior. The Journal of Social Psychology, 89, 73-77. doi:10.1080/00224545.1973.9922569

Blau, P. (1964). Exchange and power in social life. New York, NY: Wiley.

Boster, F. J., Fediuk, T., \& Kotowski, M. R. (2001). The effectiveness of an altruistic appeal in the presence and absence of favors. Communication Monographs, 68, 340-346. doi:10.1080/03637750128074

Brennan, M., \& Charbonneau, J. (2009). Improving mail survey response rates using chocolate and replacement questionnaires. Public Opinion Quarterly, 73, 368-378. doi:10.1093/poq/nfp030

Brennan, M., Hoek, J. A., \& Gendall, P. (1998). The tea bag experiment: More evidence on incentives in mail surveys. Journal of the Market Research Society, 40, 347-351. doi:10.1177/0894439304263147

Burger, J., Ehrlichman, A. M., Raymond, N. C., Ishikawa, J. M., \& Sandoval, J. (2006). Reciprocal favor exchange and compliance. Social Influence, 1, 169-184.

Burger, J., Horita, M., Kinoshita, L., Roberts, K., \& Vera, C. (1997). Effects of time on the norm of reciprocity. Basic and Applied Social Psychology, 19, 91-100. doi:10.1207/s15324834basp1901_7

Burger, J. M., Sanchez, J., Imberi, J. E., \& Grande, L. R. (2009). The norm of reciprocity as an internalized social norm: Returning favors even when no one finds out. Social Influence, 4, 11-17. doi:10.1080/15534510802131004

Cialdini, R., Vincent, J., Lewis, S., Catalan, J., Wheeler, D., \& Lee Darby, B. (1975). Reciprocal concessions procedure for inducing compliance: The door-in-the-face technique. Journal of Personality and Social Psychology, 31, $206-215$. doi: $10.1037 / \mathrm{h} 0076284$

Cialdini, R. B. (2009). Influence: Science and practice (5th ed.). Boston, MA: Pearson Education, Inc.

Dommeyer, C. J., Hirao, N., Ikeda, Y., Linkletter, N., \& Watanabe, K. (2010). Using a contingent, nonmonetary incentive to increase the response rate to a personally-initiated, self-administered survey among college students. Marketing Bulletin, 21, 1-9.

Edlund, J. E., Sagarin, B. J., \& Johnson, B. S. (2007). Reciprocity and the belief in a just world. Personality and Individual Differences, 43, 589-596. doi:10.1016/j.paid.2007.01.007

Fairweather, J. (2010). The effectiveness of a chocolate incentive in a mail survey of New Zealand farmers. Marketing Bulletin, 21, 1-9.

Foa, E. B., \& Foa, U. G. (2012). Resource theory of social exchange. In K. Törnblom \& A. Kazemi (Eds.), Handbook of social resource theory: Theoretical extensions, empirical insights, and social applications, critical issues in social justice (Vol. 15). New York, NY: Springer Science. doi:10.1007/978-1-4614-4175-5_2

Gouldner, A. W. (1960). The norm of reciprocity: A preliminary statement. American Sociological Review, 25, 161-178. doi:10.1111/j.1740-8784.2006.00047.x 
Greenberg, M. S., \& Frisch, D. M. (1972). Effect of intentionality on willingness to reciprocate a favor. Journal of Experimental Social Psychology, 8, 99-111. doi:10.1016/0022-1031(72)90028-5

Greenberg, M. S., \& Shapiro, S. P. (1971). Indebtedness: An adverse aspect of asking for and receiving help. Sociometry, 34, 290-301. doi:10.2307/2786418

Harrel, W. A., \& Goltz, J. W. (1980). Effect of victim's need and previous accusation of theft upon bystander's reaction to theft. The Journal of Social Psychology, 112, 41-49. doi:10.1080/00224545.1980.9924296

Homans, G. (1961). Social behavior as exchange. American Journal of Sociology, 63, 597-606. doi:10.1086/222355

Innes, J. M., \& Gilroy, S. (1980). The semantics of asking a favor: Asking for help in three countries. The Journal of Social Psychology, 110, 3-7. doi:10.1080/00224545.1980.9924216

Jacob, C., Guéguen, N., \& Boulbry, G. (2015). Effect of an unexpected small favor on compliance with a survey request. Journal of Business Research, 68, 56-59. doi:10.1016/j.jbusres.2014.05.008

Mauss, M. (1966). The gift. London, UK: Cohen \& West.

Perugini, M., Gallucci, M., Presaghi, F., \& Ercolani, A. P. (2003). The personal norm of reciprocity. European Journal of Personality, 17, 251-283. doi:10.1002/per.474

Regan, D. T. (1971). Effects of a favor and liking on compliance. Journal of Experimental Social Psychology, 7, 627-639. doi:10.1016/0022-1031(71)90025-4

Ridley, M. (1997). The origin of virtue: Human instincts and the evolution of cooperation. London, UK: Penguin Books.

Trivers, R. L. (1971). The evolution of reciprocal altruism. The Quarterly Review of Biology, 46, 35-57.

Whatley, M. A., Webster, J. M., Smith, R. H., \& Rhodes, A. (1999). The effect of a favor on public and private compliance: How internalized is the norm of reciprocity? Basic and Applied Social Psychology, 21, 251-259. doi:10.1207/S15324834BASP2103_8

Wright, R. (1994). The moral animal: Evolutionary psychology and everyday life. New York, NY: Pantheom Books. 